Тел.: (48131) 6-18-66.

Рогожина Анна Владимировна, преподаватель кафедры «Металлические и деревянные конструкции», Национальный исследовательский Московский государственный строительный университет. Россия.
129337, г. Москва, Ярославское шоссе, 26.

Тел.: (495) 781-80-07.

Ключевые слова: заряженная частииа; неоднородное электрическое поле; точечный источник; математическая модель; система дифференииильных уравнений; поле точечного источника.

\title{
CHARGED SIDE TRAJECTORY ANALYSIS
}

Kuzmin Konstantin Anatolyevich, Candidate of Pedagogical Sciences, Associate Professor of the chair "Science and Technical Disciplines and Information Technology", K.G. Razumovsky Moscow State University of technologies and management (the First Cossack University), Russia.

Morozov Sergey Mikhaylovich, Candidate of Technical Sciences, Associate Professor, Head of the chair "Science and Technical Disciplines and Information Technology", K.G. Razumovsky Moscow State University of technologies and management (the First Cossack University), Russia.

Rogozhina Anna Vladimirovna, Teacher of the chair "Metal and Wooden Structures", National Research Moscow State University of Civil Engineering. Russia.

Keywords: charged particle; non-uniform electric field; point source; mathematical model; differential equations system; point source field.

This article analyzes the behavior of a charged particle in the inhomogeneous electric field of a point source. A mathematical model is constructed and the solution of a system of partial differential equations is given.

удк 331.644

\section{ОБЕСПЕЧЕНИЕ БЕЗОПАСНОСТИ И НАДЕЖНОСТИ ЭЛЕКТРОСНАБЖЕНИЯ ИНЖЕНЕРНО-ТЕХНИЧЕСКИМИ МЕРОПРИЯТИЯМИ}

\begin{abstract}
ОРЛОВ Павел Сергеевич, Ярославская государственная сельскохозяйственная академия ШКРАБАК Владимир Степанович, Санкт-Петербургский государственный аграрный университет
\end{abstract}

БОБКОВ Степан Александрович, Ярославская государственная сельскохозяйственная академия

ШКРАБАК Роман Владимирович, Санкт-Петербургский государственный аграрный университет

ШЕВХУЖЕВ Анатолий Фоадович, ФГБНУ «Северо-Кавказский федеральный научный аграрный изентр»

РУЗАНОВА Наталья Игоревна, Санкт-Петербургский государственный аграрный университет

В статье излагаются пути обеспечения безопасности и надежности электроснабжения инженерно-техническими мероприятиями. Дан всесторонний анализ распространенных инженерно-технических средств безопасности и организационных мероприятий по надежности электроснабжения, соответствующих в основном требованиям нормативно-технической документации (Правилам устройства электроустановок и правилам технической эксплуатации электроустановок). Дан переченъ и анализ инженерно-технических мероприятий, способствующих рещению проблемы обеспечения электробезопасности и надежности электроснабжения предприятия и учреждений. При этом рассмотрены различные сети, используемые в практике электроснабжения разнообразных предприятий. Обращено внимание на составляющие электроснабжения и электропотребления - сети, трансформаторные подстанции, потребители электроэнергии (производство, быт и др.).

Введение. Безопасность и надежность электрообеспечения систем жизнедеятельности предприятий и учреждений страны приоритетный фактор, решающим образом влияющий на все стороны экономики, оборо- носпособности, быта и др. Поэтому им постоянно уделяется внимание во всех направлениях деятельности, что определяет актуальность проблемы в части обеспечения безопасности и надежности электроснабжения (в данном 
случае инженерно-техническими и организационными мероприятиями).

Методика исследований. Базируется на обстоятельном изучении и анализе ситуаций, имеющих место в системах жизнедеятельности предприятий и учреждений страны (включая агропромышленный комплекс). Это позволяет выявить слабые точки в системах электроснабжения, включая профилактику электротравматизма и надежность электроснабжения. Названные параметры являются определяющими в функционировании системы обеспечения энергией, влияющими на эффективность жизнедеятельности.

Результаты исследований. начительная часть повреждений в высоковольтных сетях промышленных предприятий приходится на долю однофазных коротких замыканий, составляющих от 60 до $90 \%$ от общего числа повреждений. Часть повреждений - многоместные повреждения электрооборудования, приводящие к отключению питания электроприемников сразу нескольких участков. Эти явления связаны с перемежающейся дугой в режиме однофазного замыкания на землю, сопровождающегося перенапряжениями, охватывающими всю электрическую сеть. Опасность для людей связана с появлением на металлических нетоковедущих частях электрооборудования, элементах заземляющих устройств, поверхности земли в местах однофазного замыкания на землю и в непосредственной близости от них напряжений, пропорциональных току замыкания на землю. Для уменьшения вероятности поражения электрическим током и ограничения длительности существования однофазного замыкания на землю применяют защиту, которую необходимо устанавливать на всех линиях напряжением выше 1 кВ, отходящих от подстанций и питающих передвижные электроустановки и электроприводы механизмов в цехах предприятий. Защита должна действовать на отключение поврежденной линии без выдержки времени (первая ступень защиты). Невыполнение требований Правил устройства электрооборудования (ПУЭ) или отказ защиты приводит к возникновению аварийной ситуации, характеризующейся повышенной опасностью поражения людей и вывода из строя электроустановок. Реализация резистивного заземления нейтрали позволяет решить проблемы, связанные с настройкой релейной защиты от замыканий на землю и перенапряжениями при горении однофазной дуги. ПУЭ предусматривает и обязывает эксплуатировать сети напряжением 3...35 кВ с изолированной, заземленной через резистор или дугогасящий реактор нейтралью. Использование резистора не приводит к переводу сети в разряд сетей с эффективно заземленной нейтралью, поскольку коэффициент замыкания на землю в сети с резистивно заземленной нейтралью остается равным 1,73, как и для с сетей с изолированной нейтралью. Многие энергосистемы в РФ в промышленности используют заземление нейтрали через резистор. Энергетические службы этих предприятий для снижения аварийности в питающих сетях и сокращение затрат на восстановительные ремонты и затрат от простоя оборудования считают экономически обоснованным и целесообразным использование высоковольтных резисторов, рассчитанных на решение проблем и минимизацию негативных последствий от режимов однофазного замыкания на землю. Переход к резистивно-заземленной нейтрали позволяет эффективно ограничить перенапряжения, возникающие при однофазных дуговых замыканиях до 2,2-2,6 $U_{\text {мAх Ф; }}$;окализовать устойчивые и неустйчивые феррорезонансные процессы, вызванные насыщением магнитной системы трансформаторов напряжения и возможным перегоранием их первичных обмоток; добиться глубокого ограничения коммутационных перенапряжений путем использования нелинейного ограничителя перенапряжения с меньшим остающимся напряжением и меньшей энергоемкостью, предупредить выход из строя нелинейного ограничителя перенапряжения; обеспечить снижение смещения нейтрали в сетях с дугогасящим реактором до уровня, нормированного ПТЭ (не более 15 \% и существенно ниже); повысить надежность срабатывания релейной защиты при дуговых замыканиях на землю и обеспечить ее гарантированное срабатывание при глухом замыкании (при низкоомном резисторе заземления нейтрали это достигается переводом горения перемежающейся дуги в устойчивом режиме при токе резистоpa $I_{R}=(2-4) I_{\text {С }}$ (где $I_{\text {С }}$ - емкостной ток) и селективном отключении поврежденного фидера ненаправленными токовыми защитами 
(высокоомное сопротивление $R$ позволяет обеспечить работоспособность защит на наложенном токе и направленных защитах)). Высокоомный резистор в нейтрали сети находится в постоянно включенном состоянии и рассчитан на длительный (6 ч и более) режим работы при однофазном замыкании на землю. Поэтому можно обойтись без устройств автоматики защиты для его отключения. Главная задача высокоомного резистора - ограничение перенапряжений и срыв условий возникновения феррорезонанса при выполнении условия: $I_{R}=(0,6-1,2) I_{\text {c }}$. Сети с высокоомными резисторами чаще применяют в сетях напряжением не более 10 кВ. Предприятия часто применяют комбинированную схему заземления нейтрали включением высокоомного резистора параллельно дугогасящему резистору. Это позволяет совместить плюсы сетей с компенсацией емкостного тока, решить вопрос с селективным выявлением поврежденного фидера и ограничить преренапряжения при расстройствах компенсации до 30 \%. Установка высокоомных резисторов позволяет решить проблему многоместных повреждений высоковольтных электродвигателей при однофазных замыканиях на землю. Проведенные экспериментальные исследования в сети напряжением 6 кВ для режимов изолированной и резистивно-заземленной нейтрали подтвердили эффективность резистивного заземления нейтрали со сроком окупаемости установки резисторов в течение месяца. Низкоомный резистор с активной составляющей тока в месте замыкания $\left(I_{3} \geq 40 . .50 \mathrm{~A}\right.$ рассчитан на отключение фидера с однофазными замыкателями на землю (O33) устройствами релейной защиты, действующими, как правило, с выдержкой времени 0,22,5 с. Согласно международному стандарту, время термической стойкости резистора должно быть не менее 10 с для обеспечения отключения нескольких последовательных замыканий на землю. В случае несрабатывания защит и неотключения выключателей фидера и выключателей на вводе секции резистор должен быть принудительно отключен вместе с нейтралеобразующим устройством. Схемы с низкоомным резистором для отключения всех О3З в настоящее время активно внедряются в сетях $6 . . .10$ кВ питающих подстанций 110...220 кВ. Применение низко- омных резисторов позволяет построить селективную защиту от ОЗ3 на основе токовых реле с отключением только поврежденного присоедениния и вводом резерва на стороне 6 ... 10 кВ или на стороне 0,4 кВ; минимизировать область повреждения при О3З за счет быстрого его отключения; уменьшить сроки и стоимость восстановительных ремонтов электрооборудования; предупредить несчастные случаи поражения электрическим током людей и животных. При возникновении ОЗ3 происходит отключение от центра питания не магистрали, а участка с повреждением (на распределительный пункт (РП) или трансформаторную подстанцию (ТП). Число селективных отключений снизилось в 5,2 раза (90 \% отключений - повреждения кабельных муфт). Малое количество замыканий на землю связано со стеканием избыточных зарядов через низкоомный резистор в нейтрали и устранением условий развития повреждений. Резистивное заземление нейтрали обеспечивает точную локализацию участка цепи с однофазным повреждением, поскольку активный ток от резистора протекает только через трансформатор тока нулевой последовательности (ТТНП) в поврежденном фидере. Поскольку активный ток резистора (единицы и десятки ампер) на 6 порядков отличается от активного тока проводимости изоляции кабеля относительнго земли, последний в расчетах не учитывается. Для подстанции с глухозаземленной нейтралью $R_{\text {зу }} \leq$ 0,5 Ом (п. 1.7.51 ПУЭ) напряжение на защитном устройстве (ЗУ) при условии $I_{\mathrm{B}}=I_{\mathrm{C}}$ (полный ток замыкания $17 \mathrm{~A}$ ) составит не более 8,5 В. Максимальное сопротивление ЗУ для РП и ТП согласно ПУЭ оценивают как $R_{3 \mathrm{y}} \leq 250 / I_{\text {озз }}$ (но не более 10 Ом при отсутствии на РП связи с ЗУ 0,4 кВ) и $125 / I_{\text {озз }}$ (но не более 4,0 Ом для ТП 6 $10 / 0,4$ кВ и РП при наличии такой же связи, для $I_{\mathrm{R}} \leq 12$ А и $I_{\mathrm{R}}=I_{\mathrm{C}}$ составляют 14,7 и 7,4 Ом. Выполнение требований п. 1.7.57 ПУЭ достаточно для обеспечения допустимого напряжения на ЗУ при высокоомном заземлении нейтрали. При низкоомном резистивном заземлении нейтрали сети помимо растекания на 85 \% тока ОЗ3 по оболочкам кабеля 6...10 кВ до 20 \% тока растекается по PEN-проводникам низковольтной сети, а на долю непосредственно ЗУ приходится не более 2-5 \% тока замыкания на 
землю. При использовании в кабельной сети низкоомного резистора с током до 200 А напряжение прикосновения и шага с вероятностью 0,95 не превышает 50 В, что при времени отключения однофазных повреждений до 5 с по ГОСТ 12.1.038-82 не представляет опасности. В кабельно-воздушных сетях с низкоомным резистором в нейтрали из соображений перевода перемежающейся однофазной дуги в устойчивую фазу горения («металлическое» замыкание на землю) необходимо по ГОСТ 12.1.038-82 обеспечить активный ток не менее 20 А. Но однофазное замыкание на землю ВЛ 6...10 кВ опасно изза возможности попадания человека под шаговое напряжение при обрыве провода, так как сопротивление ЗУ каждой опоры, как правило, не 30 Ом, а в 3 раза меньше и напряжение шага может оказаться недопустимо большим, но время отключения защиты 1 с сводит вероятность попадания под шаговое напряжение к нулю. Выполнение условий электробезопасности при переводе сети на резистивно - заземленную нейтраль подтверждает целесообразность применения резисторов в системах электроснабжения промышленных объектов в системах энергоснабжения 6...10 кВ, обеспечивая питание машин и оборудования как на поверхности земли, так и в шахтных выработках, так как это экономически выгодно. Срок окупаемости по затратам 3-5 лет. Положительный эффект достигается за счет снижения количества неселективных аварийных отключений и остановов технологических потребителей, сокращения времени простоев технологического оборудования и затрат на ремонт, повышения надежности схем электроснабжения и надежности срабатывания защиты [5].

Подавляющее большинство потребителей электрической энергии получает ее от трансформаторных подстанций энергетических систем. Надежность электроснабжения достигается за счет установки на подстанциях двух трансформаторов, работающих, как правило, раздельно при соблюдении условия, что любой из оставшихся в работе трансформаторов (в случае выхода из строя другого) полностью или с ограничениями обеспечивает питание потребителей. Электроснабжение (в целях уменьшения установленной мощности) осуществляется не только за счет использования номинальной мощности транс- форматоров, но и за счет их перегрузочной способности. За номинальную мощность трансформатора принимают мощность, которой он может быть нагружен непрерывно в течение всего срока службы (до 20 лет) при нормальных (нормированных ГОСТами) температурных условиях окружающей среды и допускающих (при необходимости в течение 4 - 5 часов) перегрузку трансформатора на 30-40 \% (но не более чем на 50 \%). Это предусмотрено шкалой номинальных мощностей изготавливаемых силовых трансформаторов в России, выбранной с шагом КШ = 1,6, при котором номинальная мощность установленных трансформаторов примерно на 20 \% превышает возможный минимальный уровень общей мощности используемых трансформаторов. На трансформаторных подстанциях современных предприятий значительно расширены функциональные свойства систем регулирования напряжения в целях повышения качества электроэнергии компенсацией отклонений напряжения от номинального значения непосредственно на входе приемников электроэнергии, так как длительные отклонения напряжения, даже в тех случаях, когда они не выходят за пределы допустимых значений, по ГОСТ 13109-67 (от 10 до -5 \%), вызывают значительный недовыпуск продукции, а при снижении напряжения на 15-20 \% производительность промышленных предприятий падает катастрофически. В России силовые трехфазные двухобмоточные трансформаторы общего назначения выпускаются со схемами соединения обмоток: $Y / Y \mathrm{H}, Y / \Delta$, $Y \mathrm{H} / \Delta, Y / Z \mathrm{H}, \Delta / Y \mathrm{H}$ и $\Delta / \Delta$. В трансформаторах мощностью до 2500 кВА широко применяется соединение $Y / Y \mathrm{H}$, основное достоинство которого по сравнению с соединением $\Delta / Y \mathrm{H}$ заключается в низкой стоимости и технологичности изготовления обмотки ВН, хотя, с точки зрения влияния высших гармоник и работы трансформатора при несимметричных нагрузках, предпочтительнее соединение $\Delta / Y \mathrm{H}$, а там, где не требуется вывод нулевой точки со стороны $\mathrm{HH}$, - соединение $\Delta / Y$. С аналогичной целью в трансформаторах мощностью до 250 кВА используется соединение $Y / Z \mathrm{H}$ вместо $Y / Y \mathrm{H}$, хотя в этом случае расход меди увеличивается, но при соединении обмоток трансформатора по схеме «зигзаг» при несимметричной нагрузке практически 
отсутствует искажение фазных напряжений [3].

Основные повреждения в сетях 6(10) кВ, ведущие к перерывам электроснабжения однофазные замыкания на землю, составляющие 67-92 \% от общего количества повреждений, ведущих к однофазному замыканию на землю, устраняемые выездными расчетами с отключением питающего трехфазного напряжения в сетях с изолированной и компенсированной нейтралями. Трудозатраты на восстановление нормального режима линий составляют примерно 75 \% трудозатрат на эксплуатацию, а наибольшей составляющей трудозатрат на восстановление является поиск места повреждения [1].

В последние годы в электрических сетях произошел ряд аварий с частичным отключением энергосистем. При этом наиболее тяжелые последствия отказов электрических сетей имели место при негативных природных воздействиях, связанных с тем, что нормативные требования, по которым были спроектированы линии электропередачи, не соответствуют нынешним климатическим условиям эксплуатации; на них не предусмотрены системы, обеспечивающие исключение образования гололеда. Нарастание объемов электросетевого оборудования, выработавшего свой ресурс, намного превышает темпы вывода его из работы и обновления. В результате нарушается электроснабжение вследствие перегрузки электрических сетей и выхода из строя ее элементов. Если не остановить этот процесс, то основная сеть Единой энергосистемы может потерять свою работоспособность по причине возникновения непредсказуемых массовых повреждений трансформаторов и реакторов, отказов основной коммутационной аппаратуры, которые могут приводить к превращению локальных инцидентов в тяжелые общесистемные аварии. Снижение надежности энергосистемы провоцирует рост травматизма, который в осенне-зимние периоды при эксплуатации энергоустановок в ОЗП в 2015 - 2016 гг., по сравнению с аналогичным периодом 2014 - 2015 гг., возрос в 3 раза, хотя и остался в 1,22 раза ниже аналогичного периода 2013 - 2014 гг. При этом 61 \% несчастных случаев произошел при эксплуатации электроустановок потребителей, 39 \% - в электрических сетях. Наибольшее количество несчастных случаев произошло в ходе выполнения работ на воздушных линиях электропередач, вблизи шинопроводов и электропроводок без снятия напряжения, а также в распределительных устройствах вследствие случайного прикосновения к токоведущим частям, находящимся под напряжением. Основные причины несчастных случаев: недостаточная подготовленность персонала к выполнению приемов, влияющих на безопасность работ; неэффективность мероприятий по подготовке и обучению персонала и мероприятий, обеспечивающих безопасность работ в энергоустановках; невыполнение работ по поддержанию энергоустановок в безопасном состоянии; отсутствие контроля за проведением организационных и технических мероприятий по обеспечении безопасности при эксплуатации электроустановок; личная недисциплинированность работников [4].

Повышение надежности электроснабжения потребителей первой и второй категорий обеспечивается электроэнергией от двух независимых взаимно резервируемых источников питания. Для потребителей третьей категории перерывы электроснабжения не должны превышать 1 сут. [2].

Заключение. Повышение надежности электроснабжения потребителей может быть достигнуто использованием уникальных свойств аналоговых устройств - трехфазных силовых трансформаторов, с первичной обмоткой, включенной по схеме «звезда с нулем», запитанных от четырехпроводной сети, которые при утрате питания от любого одного из четырех питающих проводов за счет неразрывности магнитных потоков автоматически восстанавливают полнофазное напряжение на вторичной и первичной обмотках трансформатора сложением магнитных потоков, генерируемых обмотками, питающимся от оставшихся двухфазных проводов в магнитопроводе обесточенной обмотки трансформатора с сохранением порядка следования фаз, распределяя трехфазную нагрузку симметрично по двум оставшимся питающим фазным проводам с превышением нагрузки по оставшимся двум фазным проводам и двум запитанным от них обмоток трансформатора не более чем на 50 \%, используя возможности трансформатора в течение 4-5 ч выдерживать перегрузку трансформатора на 30-40 \% (но не более чем 
на 50 \%) позволяя линии и трансформатору бесперебойно функционировать, повышая надежность электроснабжения потребителей даже третьей категории исключением 67-92 \% от общего количества повреждений вследствие обрыва любого одного фазного проводника или однофазного короткого замыкания на землю до устранения повреждения на линии.

\section{СПИСОК ЛИТЕРАТУРЫ}

1. Байбурин Э.Р. Повышение надежности сельских сетей 6(10) кВ на основе оперативного определения места повреждения при однофазном замыкании на землю параметрами переходного процесса без отключения потребителей: автореф. дис. ... канд. техн. наук. СПб.; Пушкин, 2006. -27 c.

2. Правила устройства электроустановок. Новосибирск, 2005. - 854 с.

3. Сергеенков Б.Н., Киселев В.М., Акимова В.А. Электрические машины. Трансформаторы. - М.: Высшая шк., 1989. - 352 с.

4. Трембиикий А.В. Почему происходят аварии. // Охрана труда и социальное страхование. 2016. - № 9. - С. 17-24.

5. Ширковец А.И., Хадыев И.Г., Кудряшов Д.С. О переводе сетей 6-10 кВ горных и металлургических предприятий на режим эксплуатации с резистивно-заземленной нейтралью // Безопасность труда в промышленности - 2016. № 1 . - С. $18-25$.

Орлов Павел Сергеевич, $\partial-p$ техн. наук, проф., зав. кафедрой «Электрификаиия», Ярославская государственная сельскохозяйственная академия. Россия.
150042, Ярославль, Тутаевское шоссе 58.

Тел.: 8-915-977-46-97.

Шкрабак Владимир Степанович, $\partial-p$ техн. наук, проф. кафедры «Безопасность технологических проиессов и производств», Санкт-Петербургский государственный аграрный универcuтет. Росссия.

196605, Санкт-Петербург - Пушкин, Петербургское шоссе, 2.

Тел.: (812) 451-76-18.

Бобков Степан Александрович, инженер, Ярославская государственная сельскохозяйственная академия. Россия.

150042, Ярославль, Тутаевское шоссе, 58.

Тел.: 8-915-977-46-97.

Шкпабак Роман Владимирович, канд. техн. наук, доцент, Санкт-Петербургский государственный аграрный университет. Россия.

196601, Санкт-Петербург - Пушкин, Петербургское шоссе, 2.

Тел.: 8-921-951-17-02.

Шевхужев Анатолий Фоадович, главный научный сотрудник, Северо-Кавказский федеральный научный аграрный цеентр, Россия.

369015, Карачаево-Черкесская Республика, 2. Черкесск, ул. Республиканская, 10.

Тел.: 8-926-810-20-99.

Рузанова Наталья Игоревна, аспирант кафедры «Безопасность технологических прочессов и производств», Санкт-Петербургский государственный аграрный университет. Россия.

196601, Санкт-Петербург - Пушкин, Петербургское шоссе, 2.

Тел.: 8-921-753-66-09.

Ключевые слова: безопасность; надежность; электроснабжение; мероприятия.

\section{ENSURING THE SAFETY AND RELIABILITY OF ELECTRICAL SUPPLY BY ENGINEERING AND TECHNICAL ACTIONS}

Orlov Pavel Sergeevich, Doctor of Technical Sciences, Professor, Head of the chair "Electrification", Yaroslavl State Agricultural Academy. Russia.

Shkrabak Vladimir Stepanovich, Doctor of Technical Sciences, Professor of the chair "Safety of Technological Processes and Productions", St. Petersburg State Agrarian University. Russia.

Bobkov Stepan Alexandrovich, Engineer, Yaroslavl State Agricultural Academy. Russia.

Shkrabak Roman Vladimirovich, Candidate of Technical Sciences, Associate Professor, St. Petersburg State Agrarian University. Russia.

Shevhuzhev Anatoly Foadovich, Chief Researcher, North Caucasus Federal Scientific Agrarian Center. Russia.

Ruzanova Natalya Igorevna, Post-graduate Student of the chair "Safety of Technological Processes and Productions", St. Petersburg State Agrarian University. Russia.

Keywords: security; reliability; power supply; measures.
The article outlines ways to ensure the safety and reliability of power supply engineering and technical measures. A comprehensive analysis of common engineering safety equipment and organizational measures for the reliability of power supply, corresponding mainly to the requirements of regulatory and technical documentation (Rules for electrical installations and rules for technical operation of electrical installations), is given. A list and analysis of engineering and technical measures to help solve the problem of ensuring electrical safety and reliability of power supply of the enterprise and institutions is given. At the same time, various networks used in the practice of power supply of various enterprises were considered. Attention is paid to the components of electricity supply and electricity consumption - networks, transformer substations, electricity consumers (production, life, etc.). 